\title{
Gene structure and expression characteristics of liver-expressed antimicrobial peptide-2 isoforms in mud loach (Misgurnus mizolepis, Cypriniformes)
}

\author{
Sang Yoon Lee and Yoon Kwon Nam
}

\begin{abstract}
Background: Liver-expressed antimicrobial peptide-2 (LEAP-2) is an important component of innate immune system in teleosts. In order to understand isoform-specific involvement and regulation of LEAP-2 genes in mud loach (Misgurnus mizolepis, Cypriniformes), a commercially important food fish, this study was aimed to characterize gene structure and expression characteristics of two paralog LEAP-2 isoforms.

Results: Mud loach LEAP-2 isoforms (LEAP-2A and LEAP-2B) showed conserved features in the core structure of mature peptides characterized by four Cys residues to form two disulfide bonds. The two paralog isoforms represented a tripartite genomic organization, known as a common structure of vertebrate LEAP-2 genes. Bioinformatic analysis predicted various transcription factor binding motifs in the $5^{\prime}$-flanking regions of mud loach LEAP-2 genes with regard to development and immune response. Mud loach LEAP-2A and LEAP-2B isoforms exhibited different tissue expression patterns and were developmentally regulated. Both isoforms are rapidly modulated toward upregulation during bacterial challenge in an isoform and/or tissue-dependent fashion.

Conclusion: Both LEAP-2 isoforms play protective roles not only in embryonic and larval development but also in early immune response to bacterial invasion in mud loach. The regulation pattern of the two isoform genes under basal and stimulated conditions would be isoform-specific, suggestive of a certain degree of functional divergence between isoforms in innate immune system in this species.
\end{abstract}

Keywords: Mud loach Misgurnus mizolepis, LEAP-2 isoforms, Development, Bacterial challenge

\section{Background}

Antimicrobial peptide (AMP) is the vital component of the innate immune system of fish as a central player in the first defense line against bacterial invasion (Magnadóttir 2006; Hancock et al. 2016). AMPs disrupt the physical integrity of microbial membranes and also they function as a modulatory effector in the innate immunity of fish (Townes et al. 2009; Li et al. 2012). Liver-expressed antimicrobial peptide-2 (LEAP-2) is the second blood-derived antimicrobial peptide, which was first identified in human (Krause et al. 2003). Similar with LEAP-1 (also termed hepcidin), LEAP-2 is cysteine-rich and predominantly

\footnotetext{
* Correspondence: yoonknam@pknu.ac.kr

Department of Marine Bio-Materials and Aquaculture, Pukyong National University, Busan 48513, South Korea
}

(c) The Author(s). 2017 Open Access This article is distributed under the terms of the Creative Commons Attribution 4.0 International License (http://creativecommons.org/licenses/by/4.0/), which permits unrestricted use, distribution, and reproduction in any medium, provided you give appropriate credit to the original author(s) and the source, provide a link to the Creative Commons license, and indicate if changes were made. The Creative Commons Public Domain Dedication waiver (http://creativecommons.org/publicdomain/zero/1.0/) applies to the data made available in this article, unless otherwise stated. exhibit selective antimicrobial activity against various microbes, and they may have potential ability to induce the hydrolysis of bacterial DNA, suggesting that LEAP-2 would be important in the modulation of fish innate immunity (Henriques et al. 2010; Li et al. 2015). In addition, most teleost species represent external fertilization and development without any close interconnection with parents, leading proposed needs of fish embryos and early larvae to protect themselves from microbial invasions (Nam et al. 2010). Potential involvements of LEAP-2s in the host protection during embryonic and early larval developments have been claimed in a few fish species (Liu et al. 2010; Liang et al. 2013). 
Insofar, LEAP-2 sequences have been isolated and characterized from a considerable number of teleost species belonging to a wide range of taxonomic positions. Most of previously reported fish LEAP-2s (including LEAP-2-like sequences available in public GenBank database) seem to share a conserved structural homology particularly regarding the core structure with two disulfide bonds in their predicted mature peptides (Chen et al. 2016). However, in spite of their structural homology, regulation of LEAP-2 gene expression under both non-stimulated (i.e. basal expression in healthy fish) and stimulated (i.e. modulation of expression in response to immune/stress challenges) conditions have been largely variable or even contradictory among fish species (Liang et al. 2013; Zhang et al. 2004; Bao et al. 2006). Moreover, unlike mammals, many fish species are thought to multiple LEAP-2 isoforms (two or three isoforms depending on species). Usually, such paralog isoforms of host defense proteins have often been reported to exhibit the certain subfunctionalization in their physiological roles related with host defense. However, comparative information on isoform-dependent or isoform-specific regulations of LEAP-2 paralog genes within a given species has been available only in a limited number of fish species (Zhang et al. 2004; Li et al. 2014; Yang et al. 2014).

Mud loach (Misgurnus mizolepis, Cypriniformes) is a commercially important, aquaculture-relevant fish in Korea with a gradually increasing market demand as a food fish (Nam et al. 2001). Mud loach, as its name indicates, usually inhabits muddy bottom of ponds, paddy fields, and creaks. Muddy bottom of their habitats may often contain abundant and diverse microbial populations, and hence, the AMP-mediated protective system should be a fundamental requirement for this fish species. Previously, we have reported the multivalent involvements of LEAP-1 (hepcidin) as a central orchestrator to modulate immunity and iron homeostasis in this species (Nam et al. 2011). In line with our goal to understand coordinated regulation of LEAP-1 and LEAP2 in mud loach, we reported here the characterization of two mud loach LEAP-2 isoforms (LEAP-2A and LEAP2B). In this study, we isolated complementary DNA (cDNA) and genomic genes including their $5^{\prime}$-flanking regions, examined tissue and developmental expression patterns, and scrutinized transcriptional responses of the two isoforms to bacterial challenge.

\section{Methods}

\section{Isolation of mud loach LEAP-2A and LEAP-2B genes}

From the mud loach liver transcriptome next generation sequencing (NGS) database (unpublished data), NGS clones showing the significant homology to previously known vertebrate LEAP-2s were collected and subjected to the contig assembly using Sequencher ${ }^{\ominus}$ software
(Gene Codes, Ann Arbor, MI, USA). Mud loach liver cDNA template was prepared by reverse transcription (RT) with oligo-d(T) primer and liver total RNA (2 $\mu \mathrm{g}$ ) using the Omniscript ${ }^{\odot}$ Reverse Transcription Kit (Qiagen, Hilden, Germany) according to manufacturer's instruction. Based on the contig sequences, two putative mud loach LEAP-2 cDNAs were isolated by reverse transcription-polymerase chain reaction (RT-PCR) using the liver cDNA template. Amplified RT-PCR products were cloned into pGEM-T easy vectors (Promega, Madison, WI, USA), and recombinant clones $(n=12)$ carrying correct insert size were subjected to sequencing. The representative cDNA sequence for each LEAP-2 isoform was confirmed again by direct sequencing of RT-PCR product amplified from mud loach liver. Oligonucleotide primers used in this study are listed in the Additional file 1: Table S1.

Based on the cDNA sequence, genomic fragment corresponding to each isoform was PCR-isolated, TAcloned, and sequenced as above. In order to get the $5^{\prime}$ and/or 3'-flanking regions of LEAP-2 isoforms, genome walking was carried out by using Universal Genome Walker ${ }^{\ominus}$ Kit (Clontech Laboratories Inc., Mountain View, CA, USA). Preparation of library and primer walking were carried out according to manufacturer's instruction. For each LEAP-2 isoform, amplified fragments were TA-cloned, sequenced, and assembled into a contig. Finally, the continuous version of genomic fragment spanning from 5 '-flanking region to $3^{\prime}$-untranslated region (UTR) was PCR-isolated. Representative genomic sequence of each isoform was determined by direct sequencing of amplified products with primer walking method.

\section{Bioinformatic sequence analysis}

Sequence homology with orthologs was examined using NCBI BLASTx (http://blast.ncbi.nlm.nih.gov/Blast.cgi). Open reading frame (ORF) of mud loach LEAP-2 isoforms were predicted with the ORF Finder program (https://www.ncbi.nlm.nih.gov/orffinder/). Amino acid sequence of each isoform was deduced from the corresponding cDNA using the same program. Parameter scores for primary structure of each LEAP-2 isoform were estimated using ExPASy ProtParam tool (http:// web.expasy.org/protparam/). ClustalW program (http:// www.genome.jp/tools-bin/clustalw) was used to carry out multiple sequence alignment of LEAP-2 isoforms along with their orthologs. Putative cleavage sites for signal peptide and propeptide were predicted with SignalP 4.1 Server (http://www.cbs.dtu.dk/services/SignalP/) and ProP 1.0 Server (http://www.cbs.dtu.dk/services/ProP/), respectively. Phylogenetic relationship among LEAP-2 isoforms (whole protein region) in the teleost lineage was inferred with Molecular Evolutionary Genetics 
Analysis tool (MEGA ver. 7.0; http://www.megasoftware. net/). Putative transcription factor (TF) binding motifs in the abalone LEAP-2A and LEAP-2B promoters were predicted with TRANSFAC ${ }^{\bullet}$ software (http://genexplain.com/ transfac; GeneXplain GmbH, Wolfenbüttel, Germany).

\section{Tissue distribution assay of LEAP-2A and LEAP-2B transcripts}

From 12 heathy female and 12 male adults (average total body weight $(\mathrm{BW})=27.1 \pm 4.6 \mathrm{~g})$, tissues including the brain, eye, fin, gill, heart, intestine, kidney, liver, muscle, spleen, skin, ovary, and testis were surgically removed. Tissue samples were immediately frozen on dry ice upon sampling and stored at $-80{ }^{\circ} \mathrm{C}$ untiled used. Total RNA was extracted from each tissue type using RNeasy plus Mini Kit (Qiagen, Hilden, Germany) according to manufacturer's recommendations including the DNase I treatment step. Purified total RNA was reverse transcribed to cDNA for quantitative reverse transcription PCR (RT-qPCR) assay to examine the distribution pattern and basal expression levels of each LEAP-2 isoform in adult tissues.

\section{Expression assay of LEAP-2A and LEAP-2B transcripts in developing embryos and early larvae}

Expression patterns of LEAP-2 transcripts during embryonic development and early larval period were examined by RT-qPCR assay. Induced spawning was performed using carp pituitary extracts according to the method described previously (Kim et al. 1994). Pooled eggs from three females were inseminated with pooled sperm collected from three males. Fertilized eggs were incubated at $25 \pm 1{ }^{\circ} \mathrm{C}$ until hatch using constant aeration (dissolved oxygen $=7 \pm 1{ }^{\circ} \mathrm{C}$ ppm). During development, embryos (approximately 200-300 embryos) were sampled at $0 \mathrm{~h}$ (just fertilized), $2 \mathrm{~h}$ (32-64 cells), $4 \mathrm{~h}$ (early blastula), $6 \mathrm{~h}$ (early gastrulation), $8 \mathrm{~h}$ (late gastrulation), $12 \mathrm{~h}$ (3-4 myotomes stage with the formation of optic vesicles), $16 \mathrm{~h}$ (12-14 myotomes stage), $20 \mathrm{~h}$ (20-22 myotomes stages with the beginning of eye lens formation), $24 \mathrm{~h}$ (tail-beating stage, almost close to hatching), and $28 \mathrm{~h}$ (hatch-out) post fertilization (HPF). After hatching, hatchlings were transferred to a new $25{ }^{\circ} \mathrm{C}$ tank $(60$ L). Larvae (approximately 100 larvae) were further sampled at day 1 (D1) and day 2 (D2, yolk sac absorption). Two independent induced spawning trials were made. From each spawning trial, sampling of embryos and larvae at each time point was carried out in triplicates (i.e., six biological replications for each developmental stage). Total RNAs were extracted from sampled embryos and larvae as above in order to perform RTqPCR analysis of LEAP-2 transcripts.

\section{In vivo bacterial challenge}

In order to examine the potential modulation of each LEAP-2 isoform in response to in vivo immune stimulatory treatment, mud loaches were experimentally challenged with Edwardsiella tarda, a causative agent for edwardsiellosis in this fish species. Freshly grown $E$. tarda (strain FSW910410; (Nam et al. 2011; Cho et al. 2009)) was washed twice with phosphate buffered saline (PBS, pH 6.8) and suspended in PBS. Individuals (average $\mathrm{BW}=12.1 \pm 3.4 \mathrm{~g} ; n=40$ in total) were intraperitoneally injected with E. tarda $\left(1 \times 10^{6}\right.$ cells/g body weight) (Nam et al. 2011). Injection volume was $200 \mu \mathrm{L}$. The same volume of PBS was also injected to 40 individuals in order to prepare the non-challenged control group. After injection, fish belonging to each group (challenged or non-challenged group) were transferred to one of two $200 \mathrm{~L}$ tanks at $25{ }^{\circ} \mathrm{C}$. Six individuals were randomly selected from both groups at 6, 12, 24, 48, 96, and $192 \mathrm{~h}$ post injection (HPI). From each individual, the liver, kidney, and spleen were surgically sampled for RT-qPCR assay of LEAP-2 isoforms.

\section{RT-qPCR assay and statistics}

Reverse transcription reaction was carried out with Omniscript $^{\ominus}$ Reverse Transcription Kit (Qiagen, Germany) with an inclusion of mud loach $18 \mathrm{~S}$ rRNA reverse primer in order to prepare a normalization control in RT product. An aliquot $(2 \mu \mathrm{L})$ of fourfold diluted cDNA template was subjected to qPCR amplification. Quantitative PCR amplification was performed with LightCyler480 ${ }^{\circ}$ Real-Time PCR System (Roche Applied Science, Mannheim, Germany) and LightCycler ${ }^{\circ}$ DNA Master SYBR Green I (Roche Applied Science, Germany). Specific amplifications of both LEAP-2 genes and 18S rRNA genes were verified with ethidium bromide-stained gel electrophoresis of amplified fragments and also confirmed with the melting curve analysis following the qPCR amplification. Each primer pair for target (LEAP-2 isoforms) and normalization control (18S rRNA) genes was confirmed to show the PCR efficiency higher than $94 \%$ based on the standard curves prepared using a serial dilution of cDNA samples. For each cDNA sample, triplicate assays were made.

Expression levels of LEAP-2 isoforms under nonstimulated conditions (i.e., tissue and developmental expression assays) were addressed as $\Delta \mathrm{Ct}$ method relative to $18 \mathrm{~S}$ rRNA control level (Nam et al. 2011; Schmittgen and Livak 2008). Differential expression of LEAP-2 isoforms in response to stimulatory treatments (i.e., bacterial challenge) was presented as the fold difference relative to the non-treated control group using the $2^{-\Delta \Delta \mathrm{Ct}}$ method (Nam et al. 2011; Schmittgen and Livak 2008). Significant differences in expression levels between or among groups were tested using student's $t$ 
test or one-way ANOVA (followed by Duncan's multiple ranged tests) at $P=0.05$ level.

\section{Results and discussion}

Mud loach LEAP-2 cDNA and amino acid sequences

Mud loach LEAP-2A (designated based on molecular phylogeny, see below) cDNA exhibited 268-bp 5'-UTR, 282-bp ORF encoding a polypeptide comprising 93 amino acids (aa) and a long, 966-bp 3'-UTR including 19-bp poly $(\mathrm{A}+)$ tail. A putative polyadenylation signal (AATAAA) was found at $24 \mathrm{bp}$ upstream from the poly $(\mathrm{A}+)($ GenBank accession no. KX372543). The whole protein of LEAP-2A revealed $10.54 \mathrm{KDa}$ of calculated molecular mass and 9.23 of theoretical pI value. As previously known in other LEAP-2 orthologs, mud loach LEAP-2A showed potential cleavage sites for signal peptide (between ${ }^{28} \mathrm{Cys}$ and ${ }^{29} \mathrm{Ser}$ ) and propeptide (between ${ }^{52} \mathrm{Arg}$ and $\left.{ }^{53} \mathrm{Met}\right)$, respectively. As a result, the mature peptide of mud loach LEAP-2A (44 aa) was estimated to have $4.62 \mathrm{kDa}$ of molecular weight and 8.88 of $\mathrm{pI}$ value (Fig. 1). On the other hand, mud loach LEAP-2B cDNA was comprised of 33-bp 5'-UTR, 279-bp ORF, and 546bp 3'-UTR including 25-bp poly(A+) tail. A polyadenylation signal (AATAAA) was found at -16 bp from the poly $(\mathrm{A}+)$ tail (KX372544). LEAP-2B encoded a 91-aa polypeptide $(10.36 \mathrm{KDa}$ and $\mathrm{pI}=8.38)$. Signal peptide cleavage was predicted at the site between ${ }^{27} \mathrm{Ser}$ and ${ }^{28} \mathrm{Val}$, while propeptide cleavage site was between ${ }^{50} \mathrm{Arg}$ and ${ }^{51}$ Met. Resultant 41-aa mature peptide (LEAP-2B) showed the $4.66 \mathrm{KDa}(\mathrm{Mw})$ and 6.68 (pI) (Fig. 1). Mud loach LEAP-2A and LEAP-2B shared only a low sequence identity (38.7\%) of each other at amino acid level through the entire protein region. However, when only mature peptides considered, the sequence identity between the two isoforms was $61.0 \%$. Both mud loach LEAP-2 isoforms conserved the four Cys residues predicted to form two disulfide bonds $\left({ }^{69} \mathrm{Cys}-{ }^{80} \mathrm{Cys}\right.$ and ${ }^{75} \mathrm{Cys}-{ }^{85} \mathrm{Cys}$ for LEAP-2A and ${ }^{67} \mathrm{Cys}-{ }^{78} \mathrm{Cys}$ and ${ }^{73} \mathrm{Cys}-$ ${ }^{83} \mathrm{Cys}$ for LEAP-2B) (Fig. 1), which is a typical feature of almost previously known LEAP-2 orthologs (Henriques et al. 2010; Li et al. 2015).

Mud loach LEAP-2 isoforms (mature peptide region) were further aligned with sequences of representative teleostean LEAP-2 orthologs (Additional file 2: Figure S1A). In the alignment, all the LEAP-2s except one isoform sequence from common carp Cyprinus carpio (XP_018919135, assumed to be a carp LEAP-2C variant) reveal the four Cys residues involved in two disulfide bonds at clearly conserved positions. In overall, high degree of sequence homology among orthologs was observed within a given isoform type (LEAP-2A, LEAP-2B, or LEAP-2C). LEAP-2A mature peptides were consisted of either 41 aa or 46 aa, while mature LEAP-2Bs were uniform to be 41 aa, except an ortholog ( 40 aa) from northern pike Esox lucius (Esociformes). On the other hand, lengths of LEAP-2C isoforms were variable depending on species, ranging from 34 aa to 40 aa. A closer look into LEAP-2 isoforms from fish species belonging to Cypriniformes indicated that cypriniform LEAP-2s would display isoform-dependent $\mathrm{pI}$ ranges (8.48-8.88 for LEAP-2A, 6.78-7.69 for LEAP-2B, and 9.06-9.20 for LEAP-2C) (Additional file 2: Figure S1B). In general, mature peptides of AMPs represent positively charged, cationic characteristics because they should bind to anionic microbial membranes (Hancock et al. 2016; Townes et al. 2009). With this context, the noncationic charge of cypriniform LEAP-2Bs might suggest the possibility of potential divergences with regard to their roles in the immune system. From our survey of $\mathrm{pI}$ values of other teleostean LEAP-2B isoforms (mature peptide region), such non-cationic pI values were hardly seen in orthologs from other teleost taxa (data not

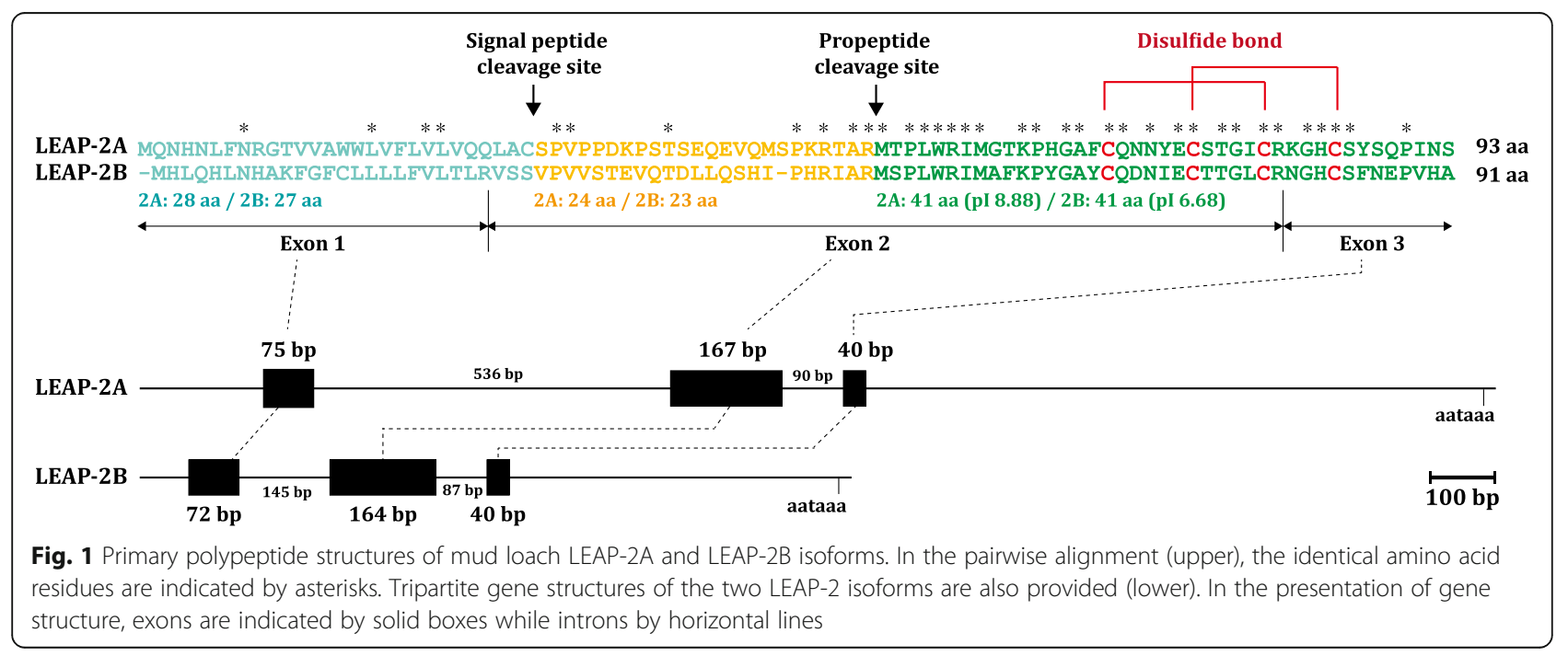


shown). Within the cypriniform group, the low $\mathrm{pI}$ values of LEAP-2Bs would be caused by the replacement of positively charged ${ }^{13} \mathrm{His}$ in LEAP-2A with uncharged Tyr in LEAP-2B as well as substitutions of uncharged ${ }^{19}$ Asn and ${ }^{37} \mathrm{Gln}$ (in LEAP-2A), respectively, to negatively charged Asp and Glu (in LEAP-2B). Hence, further structural and functional studies are needed for gaining deeper insight into the consequences of these changes.

Molecular phylogenetic analysis of teleosts LEAP-2 isoforms (with entire protein region) resulted that LEAP-2 sequences were clustered into main clades according to isoform types (i.e., LEAP-2A, LEAP-2B, and LEAP-2C) (Fig. 2). In overall tree topology, LEAP-2A and LEAP-2B were more closely affiliated, while LEAP-2C exhibited an independent group separately. From the phylogenetic tree, teleostean LEAP-2C isoforms formed a single, main clade supported by the high bootstrap confidence value, whereas both LEAP-2As and LEAP-2Bs were found to be non-monophyletic. LEAP-2As from species belonging to Neoteleostei formed an independent group (labeled LEAP-2A-(2)) separated from another group consisting of other LEAP-2As (i.e., orthologs from Ostariophysi, Protacanthopterygii, Stomiatii, and an anguilliform species; LEAP-2A-(1)). On the other hand, LEAP-2Bs were assigned into two groups; one was protacanthopterygian group comprising of species belonging to Esociformes or Salmoniformes (labeled LEAP-2B-(1) in Fig. 2), and the other was ostariophysian group consisting of species belonging to Cypriniformes or Characiformes (labeled LEAP-2B-(2)). Taken together, our molecular phylogenetic results suggest that evolutionary divergences among LEAP-2 isoforms might be lineage-dependent in this infraclass group Teleostei. Based on this molecular phylogeny, the two LEAP-2 paralogs from the mud loach should be designated as members of ostariophysian LEAP-2A and LEAP-2B, respectively. Within an isoform group, mud loach LEAP-2A and LEAP-2B isoforms were closely affiliated respectively with orthologs from other cypriniform species.

The number of LEAP-2 isoforms in a given species has been reported to be species-specific, although majority of fish species are likely to possess two functional LEAP-2 isoforms (usually LEAP-2A/LEAP-2B or LEAP2A/LEAP-2C). For example, only one LEAP-2 isoform was reported as a single copy gene in channel catfish, Ictalurus punctatus (Bao et al. 2006), whereas three isoforms (LEAP-2A, LEAP-2B, and LEAP-2C) were identified in Salmoniformes (rainbow trout Oncorhychus mykiss and Atlantic salmon Salmo salar) (Zhang et al. 2004). From the molecular phylogeny inferred in the present study, common carp C. carpio and zebrafish Danio rerio also seemed to possess three LEAP-2 isoforms. Furthermore, our data suggest that several fish species display multiple subisoform copies within a given
LEAP-2 isoform type, as particularly exemplified in common carp and salmoniform species (rainbow trout and Atlantic salmon). Those species are known to have experienced additional whole genome duplication (WGD; 50-80 million years ago (mya) for common carp and 5.6-11.3 mya for Salmoniformes) after a WGD event for the occurrence of divergent teleost fishes (320-350 mya) (Glasuer and Neuhauss 2014). Another example for multiple subisoforms of LEAP-2 could be observed in LEAP-2A and LEAP-2C isoforms from large yellow croaker Larimichthys crocea belonging to Eupercaria (Neoteleostei). Because this taxonomic group is not thought to have undergone additional WGDs, the presence of multiple LEAP-2 subisoforms in this fish species might be due to the gene-specific duplication(s) during its adaptive evolution. Duplication and/or amplification of AMP genes in certain Eupercaria fish groups have been previously reported with a proposed explanation based on the positive Darwinian selection (i.e., an adaptive evolutionary process directed by pathogens when the host fish is exposed to new environments) (Padhi and Verghese 2007), as highlighted by diversified hepcidin (LEAP-1) isoforms and subisoforms in those fish species (Cho et al. 2009; Yang et al. 2007; Lee and Nam 2011). Currently, it is unclear whether or not mud loach possesses additional LEAP-2 isoform (i.e., LEAP-2C) and/or subisoforms. However, we have not yet found LEAP-2Clike sequence from our several rounds of NGS analyses for mud loach transcriptomes.

\section{Gene structure and promoter characteristics}

Both mud loach LEAP-2A (KX372541) and LEAP-2B (KX372542) genes showed a tripartite structure (three exons) that is also the common organization of previously reported vertebrate LEAP-2 genes (Fig. 1) (Li et al. 2014). For mud loach LEAP-2A gene, three exons (75bp exon-1, 167-bp exon-2, and 40-bp exon-3) were interrupted by two introns (536-bp intron-1 and 90-bp intron-2). Mud loach LEAP-2B exhibited similar lengths for its three exons $(72,164$, and $40 \mathrm{bp}$ for exon-1, exon2 , and exon-3). However, the intron-1 (145 bp) of mud loach LEAP-2B gene was significantly shorter than that of LEAP-2A gene. For each of mud loach LEAP-2 isoform genes, exon sequences clearly matched the coding region of its corresponding cDNA counterpart. The GTAG exon-intron junction rule was consistently upheld for each boundary region. Bioinformatic analysis predicted various TF binding motifs on $5^{\prime}$-flanking regions of mud loach LEAP-2 isoform genes (Additional file 3: Table S2). They included sites targeted by aryl hydrocarbon receptor (AhR), activator protein-1 (AP-1), activating transcription factor-2 (ATF-2), CCAAT-enhancer binding protein $(\mathrm{C} / \mathrm{EBP})$, cyclic AMP-responsive element binding protein (CREBP), hypoxia inducible factor-1 (HIF- 


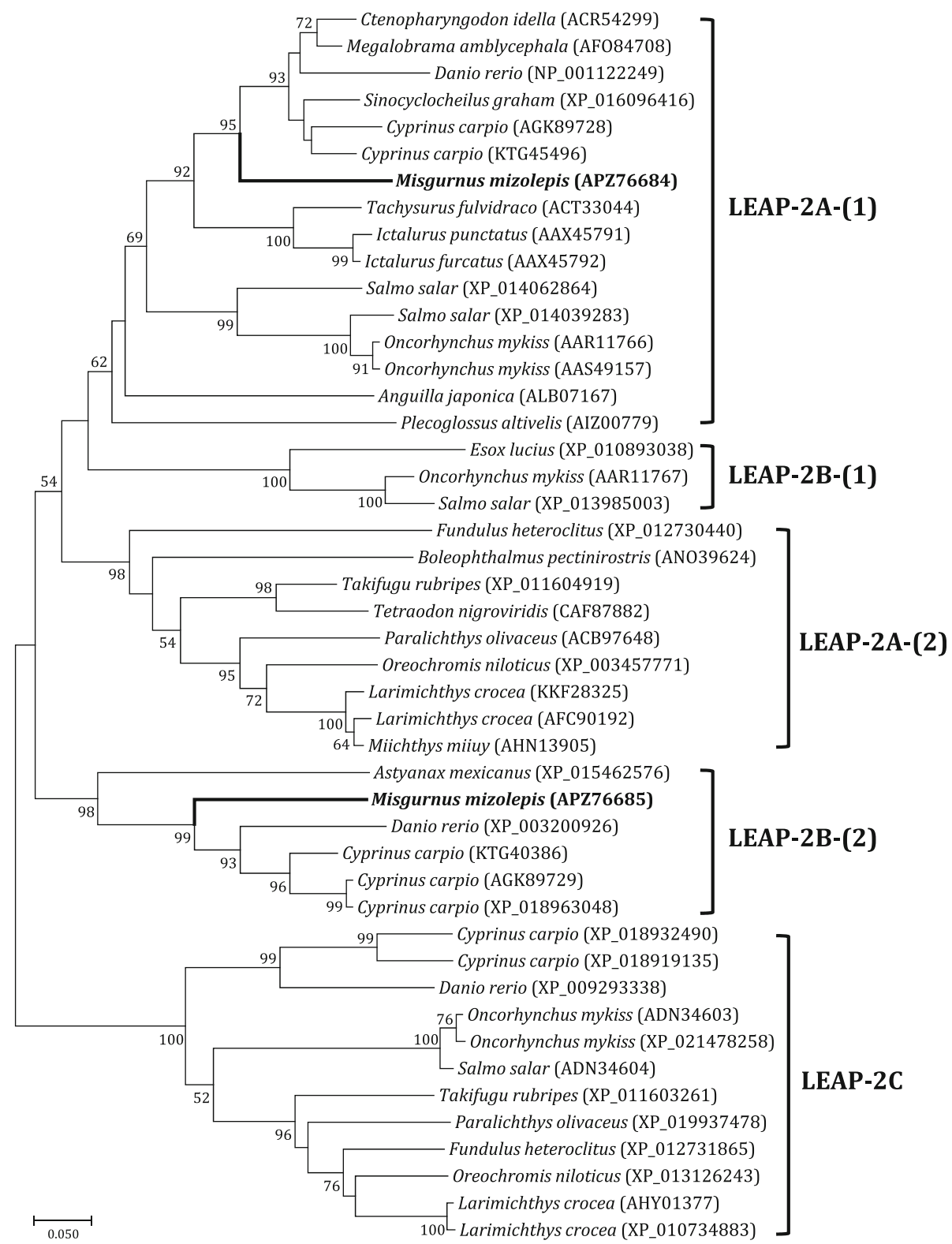

Fig. 2 Molecular phylogenetic relationships among teleostean LEAP-2s. Neighbor-joining tree was drawn with complete amino acid sequences of LEAP-2s from representative teleosts using MEGA7 software (ver. 7.0.26). Tree topology was tested by bootstrap tests (1000 replicates), and only bootstrap values higher than $50 \%$ are shown

1), interferon regulatory factor (IRF), nuclear factor of activated $\mathrm{T}$ cells (NF-AT), and signal transducer and activated transcription factor (STAT). Although functional recruitments of these transcription factors to the regulatory regions of mud loach LEAP-2 genes should be explored in future, all of them have been already known to be closely involved in immune modulation and stress response (Cho et al. 2009; Truksa et al. 2009). They have been reported to be frequently found in the $5^{\prime}$-flanking regions of acutephase battery of genes (Nam et al. 2011). However, a clear-cut distinction between mud loach LEAP-2A and LEAP-2B isoforms based on the predicted TF binding profiles is almost impossible at this moment, suggesting the need of further empirical analyses and functional typing. Besides the immune/stress-related TFs above, both mud loach LEAP-2 isoforms also exhibited diverse TF binding motifs related with cell proliferation, organ development, and reproduction such as caudal type homeobox (CdxA), distal-less homeobox (Dlx) group, Krüppel-like factor 6 (KLF6), similar to mothers against decapentaplegic (SMAD) 
factors, and sex determining region $\mathrm{Y}$ box (SOX) factors (Beck and Stringer 2010; Panganiban and Rubenstein 2002; Matsumoto et al. 2006; Budi et al. 2017; Boweles et al. 2000). It is suggestive of that LEAP-2s may play roles in ontogenic development and possibly also in gonad development of this species. Potential involvement of LEAP-2 in the developmental process including the prediction of similar TF binding motifs has been proposed in several fish species (Liu et al. 2010; Bao et al. 2006).

\section{Expression pattern in adult tissues}

Based on RT-qPCR assay, mud loach LEAP-2A transcripts were detectable in a wide range of tissue; however, basal expression levels significantly varied across tissue types (Fig. 3a). The organ showing the most robust expression of LEAP-2A transcripts was not the liver; rather, the highest expression level was found in the ovary (more than twofold relative in the liver). This highest expression in the ovary was followed by those in the liver, testis, intestine, and skin. The muscle displayed
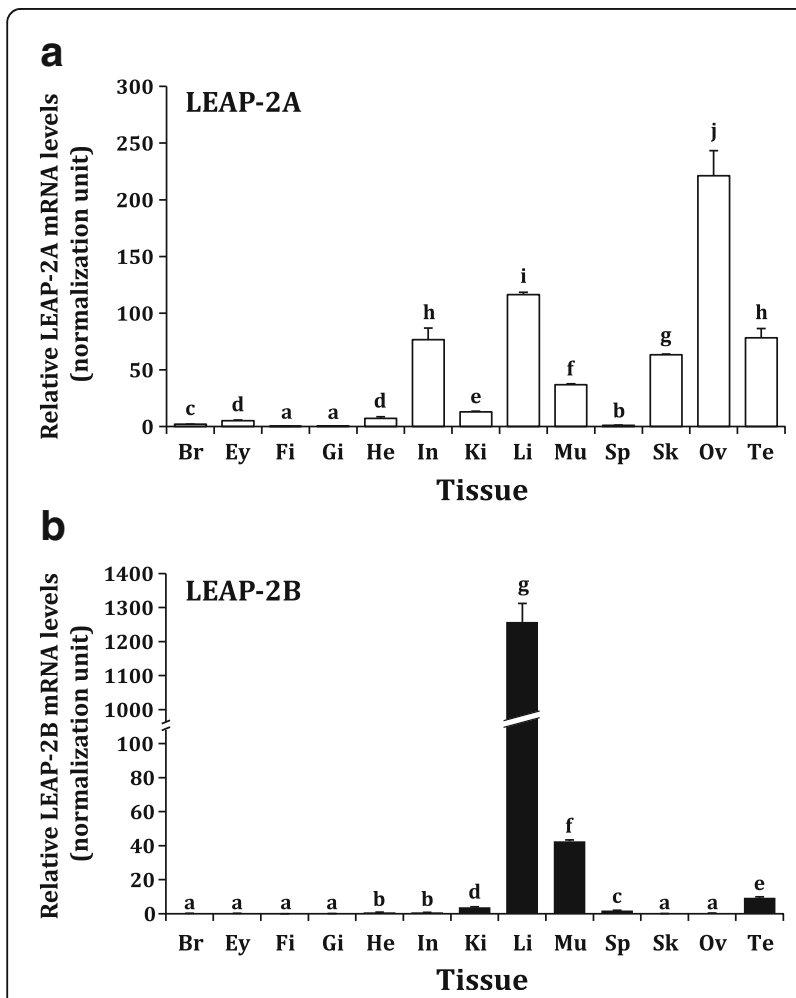

Fig. 3 Tissue distribution patterns and basal expression levels of mud loach LEAP-2A (a) and LEAP-2B (b) transcripts, as determined by RT-qPCR assay. Expression levels were normalized against $18 \mathrm{~S}$ rRNA gene. Tissue abbreviations are brain (Br), eye (Ey), fin (Fi), gill $(\mathrm{Gi})$, heart $(\mathrm{He})$, intestine $(\mathrm{In})$, kidney $(\mathrm{Ki})$, liver $(\mathrm{Li})$, muscles $(\mathrm{Mu})$, spleen (Sp), skin (Sk), ovary (Ov), and testis (Te). Statistically different means ( \pm s.d.) are indicated by different letters (a-j in (a) and a-g in (b)) based on ANOVA followed by Duncan's multiple ranged tests $(P<0.05)$. T bars indicate standard deviations a moderate level of LEAP-2A transcripts. The remaining other tissues showed only a weak expression of LEAP2A. On the other hand, LEAP-2B displayed the apparently different pattern of tissue expression compared to LEAP-2A (Fig. 3b). LEAP-2B transcripts were predominantly expressed in the liver, and the hepatic mRNA level of LEAP-2B was more than 10-fold relative to that of LEAP-2A. Except a modest expression level in the muscle, the mRNA expression of LEAP-2B was readily low or minute in all other non-liver tissues. This finding suggests that two paralog LEAP-2A isoforms have undergone certain functional differentiation in their tissue-dependent roles. For example, the strong expression of LEAP-2A in the ovary suggests its presumed roles in female reproductive immunity to protect the ovary against bacterial invasion during ovarian development and maturation. Similarly, even not as much as in the ovary, LEAP-2A showed a fairly high expression level in the mud loach testis, which is suggestive of certain protective roles in male reproduction in this species. Insofar, basal expression data of LEAP-2s in fish gonads have been limited. Our finding on the strong expression of LEAP-2A in the mud loach ovary was similar with the observation from the grass carp Ctenopharyngodon idella (Liu et al. 2010), however, apparently different from findings in common carp $C$. carpio (Yang et al. 2014) and blunt snout bream Megalobrama amblycephala (Liang et al. 2013) to represent very low or negligible expression of LEAP-2 in gonadic tissues. Meanwhile, the protective role of a hepcidin (LEAP-1) isoform in male reproductive immunity has been reported in the mudskipper Boleophthalmus pectinirostris (Li et al. 2016).

On the other hand, the liver-predominant expression with abundant amounts of LEAP-2B may indicate that its main playground would be focused on the liver rather than other systematic or mucosal lymphoid tissues. Tissue expression pattern of LEAP-2 has been reported to be species-specific. Certain teleost species have been reported to express LEAP-2 exclusively in the liver (e.g., rainbow trout O. mykiss) (Zhang et al. 2004), while other fish species showed a wide distribution of LEAP-2 transcripts in various tissues including the liver (Bao et al. 2006; Ren et al. 2014). Furthermore, the liver has not been always the main organ showing the highest or predominant expression of LEAP-2s. Channel catfish (I. punctatus) (Bao et al. 2006) and yellow catfish (Pelteobagrus fulvidraco) (Ren et al. 2014) exhibited very low expression of LEAP-2 in their liver. Blunt snout bream ( $M$. amblycephala) (Liang et al. 2013) and large yellow croaker (Larimichthys crocea) (Li et al. 2014) showed the highest expression of LEAP-2 in midgut and intestine, although there was also robust expression of LEAP-2 in the liver. Other species such as miiuy croaker 
(Miichthys miiuy) (Liu et al. 2014) and mudskipper (B. pectinirostris) (Chen et al. 2016) displayed the strongest expression of LEAP-2 in the liver.

\section{Expression pattern in developing embryos and early larvae}

Expression of mud loach LEAP-2A was hardly detectable in early stages of embryonic development until $12 \mathrm{HPF}$ (Fig. 4a). Active transcription for LEAP-2A began to be observed from $16 \mathrm{HPF}$, gradually elevated with development until 24 HPF and sharply increased to reach the peak at hatch-out stage ( $28 \mathrm{HPF}$, day 0 ). Afterward, the expression level of LEAP-2A during the yolk sac absorption period was decreased down until 2 days after hatching (day 2). The expression of LEAP-2B was also not active in early developmental stages. Clear sign for its transcription began to be found at $8 \mathrm{HPF}$, and a small peak was formed at $12 \mathrm{HPF}$. After that, the expression level of LEAP-2B was kept to be constantly low until hatching. However, after hatching, the transcription of

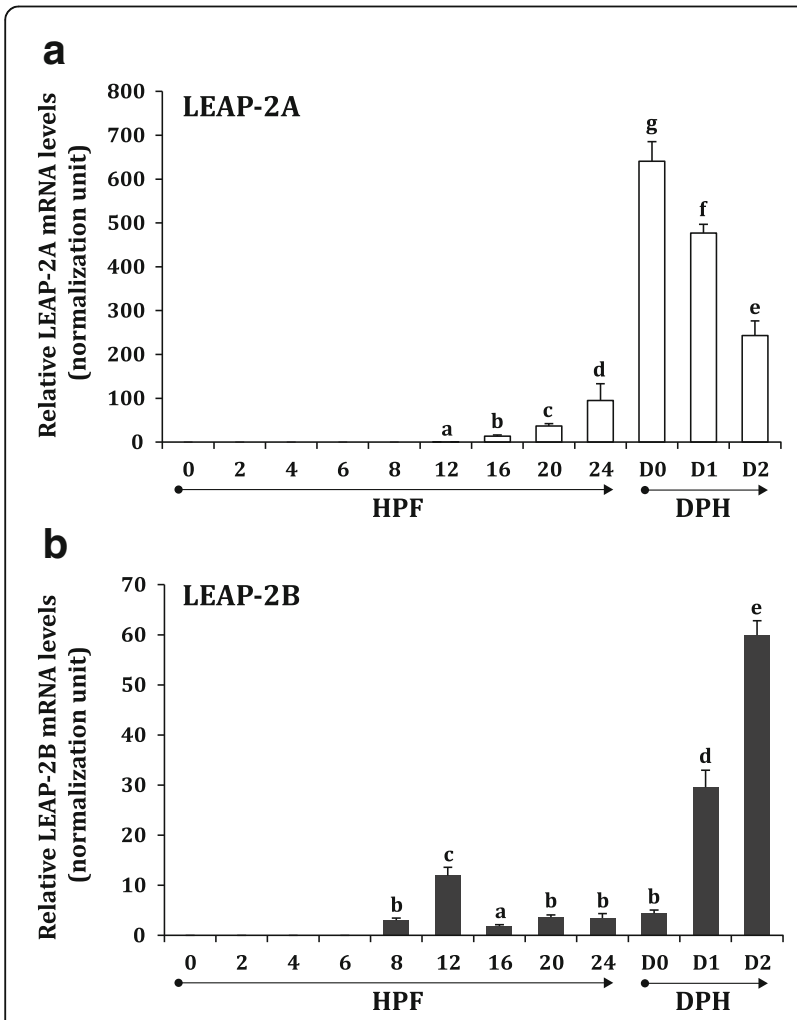

Fig. 4 Altered mRNA levels of mud loach LEAP-2A (a) and LEAP-2B (b) during embryonic development (0 to $28 \mathrm{~h}$ post fertilization, HPF) and early larval development up to 2 days post hatching (DPH) at $25^{\circ} \mathrm{C}$, as judged by RT-qPCR assay. Day 0 (D0) is the time of just hatching corresponding to $28 \mathrm{HPF}$. Expression levels were normalized against 185 rRNA gene. LEAP-2 transcripts were not detected at early stages of development. Statistically different means ( \pm s.d., as $T$ bars) are indicated by different letters ( $\mathrm{a}-\mathrm{g}$ in LEAP-2A and $\mathrm{a}-\mathrm{e}$ in LEAP-2B) based on ANOVA followed by Duncan's multiple ranged tests $(P<0.05)$
LEAP-2B began to be rapidly stimulated with a remarkable increase of its transcript level until day 2 (Fig. 4b).

Our data indicate that transcripts of both LEAP-2 isoforms would be little detected in the developmental period from early cleavages to blastula stage, suggesting that there was no significant contribution of maternally transmitted LEAP-2 copies to these early embryos. This finding is in accordance with the observations made with channel catfish, in which mature LEAP-2 mRNAs would be detectable only after hatching (Bao et al. 2006). However, in contrast, our finding on developmental expression is largely different from those of other previous studies to report active expression of LEAP-2 transcripts in early embryos, as exemplified by grass carp (early detection at 16-cell stage) (Liu et al. 2010) and blunt snout bream (expression level peaked at mid-gastrula) (Liang et al. 2013). Collectively, the developmental regulation of LEAP-2 genes in early embryos might be species-specific, although the information on the developmental expression of LEAP-2 genes in teleosts has been still limited to only couples of species (Liu et al. 2010; Liang et al. 2013; Bao et al. 2006). Additionally, in channel catfish, LEAP-2 gene has been reported to be regulated at the level of splicing where the primary transcripts would remain unspliced until 6 days after hatching (Bao et al. 2006). However, we have not yet found differentially spliced transcripts of LEAP-2 in mud loach.

On the other hand, the significant upregulation of mud loach LEAP-2 isoforms around the hatching event (from the prophase of hatching to day 1 for LEAP-2A, and from the post hatching to day 2 for LEAP-2B) is broadly congruent with findings from most of previous studies, essentially including findings in grass carp (Liu et al. 2010) and blunt snout bream (Liang et al. 2013). More specifically, the pattern of mud loach LEAP-2A is obviously similar with that of blunt snout bream LEAP2 in terms of that the peak of expression level at hatched larvae was declined with the progress of early larval development (Liang et al. 2013). On the other hand, expression pattern of mud loach LEAP-2B is similar with that of grass carp in the sense that no decrease of expression in post hatched larvae (Liu et al. 2010), suggesting that developmental modulation of LEAP-2 in teleosts may be an isoform-dependent as well as specific-specific.

Rapid upregulation of AMPs including LEAP-2 isoforms at hatching phase is generally explained by the preparation of antimicrobial and/or immune modulatory function for hatched larvae that are no longer protected from the egg membrane (Liang et al. 2013). Besides LEAPs, active expression of multiple beta-defensin isoforms and cathelicidin in early larval stages have also been characterized in olive flounder Paralichthys olivaceus (Nam et al. 2010) and Atlantic cod Gadus morhua (Broekman et al. 2011). In this loach species, the main 
LEAP-2 isoform to confer defensive function on newly hatched larvae might be LEAP-2A based on its much higher expression level than LEAP-2B counterpart. However, with progress of ontogenic development of post hatched larvae, the roles of LEAP-2B seem to become important, which is also in agreement with the period when the liver begins to be developed in loach species belonging to genus Misgurnus (Fujimoto et al. 2006; Kim et al. 1987). LEAP-2B may also have a certain role in onset of myogenic development as inferred by its upregulation at the 3-4 myotome stages; however, the mechanism behind this finding should be clarified in future.

\section{Differential expression in response to bacterial challenge}

Under present challenge conditions, mortality was found in neither $E$. tarda-challenged group nor PBS-injected group, although some pathological symptoms could be observable in a few E. tarda-injected individuals at 96 and 192 HPI (photos not shown).

Upon E. tarda challenge, LEAP-2A was rapidly upregulated in all the three tissues (the liver, kidney, and spleen) examined. Induced fold change relative to nonchallenged fish was the highest in the liver (up to 20-fold at $12 \mathrm{HPI}$ ), and this highest induction was followed by that in the kidney (more than eightfold at $12 \mathrm{HPI}$ ) (Fig. 5a). In the spleen, the upregulation of LEAP-2A was not significant (only 1.5 -fold) compared to fold inductions observed in the liver and kidney. Considering the time course expression pattern, the induction of LEAP-2A is an early response during bacterial invasion, as evidenced by the apparent upregulation of LEAP-2A as early as 6 HPI. Increased level of LEAP-2A transcripts in early phase was decreased down to control levels at late phases (i.e., 48, 96, and $192 \mathrm{HPI}$ ). This expression pattern was broadly in agreement with the previous observations made in yellow catfish (challenged with $E$. tarda) (Ren et al. 2014) and large yellow croaker (challenged with Vibrio alginolyticus) (Li et al. 2014).

Mud loach LEAP-2B also followed, in general, the early response pattern in terms of the rapid induction at 6-12 HPI in all the three tissues and subsequent decreases in late phases (Fig. 5b). However, even downregulated in later phases, LEAP-2B showed a tendency of more persistent expression pattern, compared to LEAP-2A. Unlike LEAP-2A showing the rapid drop of its transcripts soon after early induction (i.e., recovery to control level at $48 \mathrm{HPI}$ in the liver and kidney), the mRNA expression levels of LEAP-2B were still higher than control level until 96 HPI in all the three tissues, although there was a rebound of expression (i.e., at 48 HPI in the kidney and at 24 HPI in the spleen). Isoformdependent difference in the time course modulation of LEAP-2 genes in this study is similar with the previous finding on the expression pattern of large yellow croaker LEAP-2 isoforms (Li et al. 2014). During the challenge using $V$. alginolyticus in large yellow croaker, one
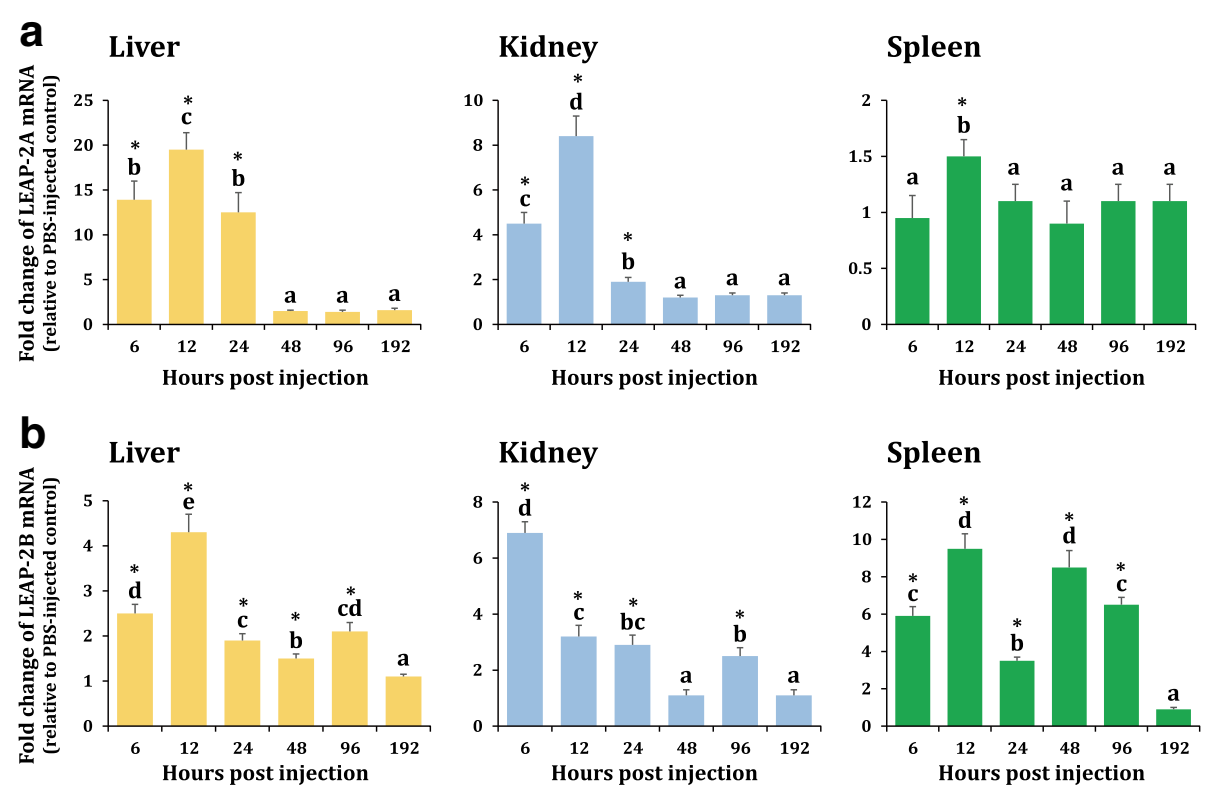

Fig. 5 Differential expression patterns of mud loach LEAP-2A (a) and LEAP-2B (b) in the liver, kidney, and spleen during experimental challenge with Edwardsiella tarda. Expression levels of E. tarda-challenged group are presented as fold change relative to PBS-injected control based on RT-qPCR assay. Statistically different means ( \pm s.d.) are indicated by different letters based on ANOVA followed by Duncan's multiple ranged tests $(P<0.05)$. Asterisks indicate statistically different expression levels $(P<0.05)$ of $E$. tarda-injected group when compared to expression levels of PBS-injected control group based on student's $t$ test 
isoform (LEAP-2A) is rapidly upregulated in early phase and afterward declined, while the other isoform (LEAP2C) is gradually upregulated with the time after challenge ( $\mathrm{Li}$ et al. 2014). In addition, expression pattern between mud loach LEAP-2A and LEAP-2B isoforms was apparently different in the spleen. In contrast to only the modest increase of LEAP-2A in the spleen, LEAP-2B was significantly upregulated by bacterial challenge (up to 10-fold relative to non-challenged control). It suggests that isoform-specific involvement in innate immune pathways may differ depending on tissue types. Previously, channel catfish LEAP-2 has been reported to be moderately upregulated in the spleen during $E$. ictaluri challenge, but not differentially modulated in the kidney and liver (Bao et al. 2006). Transcriptional responses of fish LEAP-2 genes to bacterial challenge have been known to be variable among tissues and species. Although bacterial challenges have been reported usually to induce the transcription of LEAP-2 genes in diverse tissues of fish essentially including the liver, there have been also some exceptional or contradictory results in several fish species. For example, rainbow trout was found to display induced expression of LEAP-2 genes only in non-liver tissues such as intestine and skin (Zhang et al. 2004). One isoform of common carp LEAP-2 (LEAP-2B) was significantly downregulated in the liver during $V$. anguillarum challenge unlike its paralog counterpart LEAP-2A showing the highest induction of the expression during the same bacterial challenge (Yang et al. 2014).

Overall, data form bacterial challenge experiment in this study suggest that both mud loach LEAP-2 isoforms are potentially associated with the early response to bacterial invasion, in which their involvements may be tissue- and isoform-dependent (i.e., induction of LEAP$2 \mathrm{~A}$ mainly in the liver and LEAP-2B in the spleen). However, in order to better hypothesize subfunctionalization(s) between the two LEAP-2 isoforms as antimicrobial components of acute-phase battery in innate immunity, further study should be needed particularly with regard to the evaluation of actual bactericidal activity of each isoform (Hancock et al. 2016; Li et al. 2012). In addition, further study on the possible divergence of the two LEAP-2 isoforms as immune modulatory effectors (i.e., effects of LEAP-2 isoforms on the modulation of expression for other immune-related genes) (Katzenback 2015) would be valuable to get a deeper insight into the genetic pathways interconnected with LEAP-2s in this species.

\section{Conclusions}

Two novel isoforms for liver-expressed antimicrobial peptide-2 (LEAP-2A and LEAP-2B) were isolated from a mud loach (Misgurnus mizolepis, Cypriniformes). Based on molecular characterization of gene structure and bioinformatic analysis, the two mud loach LEAP-2 genes share conserved characteristics with their orthologs in the teleost lineage. Our findings from expression analyses suggest that both LEAP-2 isoforms play host defense roles not only in early larval developments but also in acute immune response to invading bacteria in adults. Expression assay also indicates the two paralog genes exhibit isoform-specific regulations particularly in a tissuedependent manner. Data from this study could be a fundamental basis to understand functional involvements of LEAP-2s in the innate immune system of mud loach.

\section{Additional files}

Additional file 1: Information on oligonucleotide primers used. (PDF $97 \mathrm{~kb}$ )

Additional file 2: Sequence alignment and phylogenetic analysis. (PDF 296 kb)

Additional file 3: Transcription factor prediction in LEAP-2 gene promoter. (PDF $122 \mathrm{~kb}$ )

\section{Abbreviations}

AMP: Antimicrobial peptide; DPH: Days post hatching; HPF: Hours post fertilization; HPI: Hours post injection; LEAP-2: Liver-expressed antimicrobial peptide-2; ORF: Open reading frame; RT: Reverse transcription

\section{Acknowledgements}

Not applicable

\section{Funding}

This study was supported by the grant from the Korea Institute of Marine Science \& Technology Promotion (KIMST, project no. 20130369).

\section{Availability of data and materials}

Not applicable

\section{Authors' contributions}

SYL carried out the molecular cloning and gene expression analyses. YKN designed the study, performed the bioinformatic analyses, and drafted the manuscript. Both authors read and approved the final manuscript.

Ethics approval and consent to participate

Experimental protocols followed the guidelines of the Animal Care and Use Committee of Pukyong National University.

Consent for publication

Not applicable

\section{Competing interests}

The authors declare that they have no competing interests.

\section{Publisher's Note}

Springer Nature remains neutral with regard to jurisdictional claims in published maps and institutional affiliations.

Received: 20 August 2017 Accepted: 31 October 2017

Published online: 04 December 2017

\section{References}

Bao B, Peatman E, Xu P, Li P, Zeng H, He C, Liu Z. The catfish liver-expressed antimicrobial peptide 2 (LEAP-2) gene is expressed in a wide range of tissues and developmentally regulated. Mol Immunol. 2006;43:367-77. 
Beck F, Stringer $\mathrm{E}$. The role of $\mathrm{Cdx}$ genes in the gut and in axial development. Biochm Soc Trans. 2010;38:353-7.

Boweles J, Schepers G, Koopman P. Phylogeny of the SOX family of developmental transcription factors based on sequence and structural indicators. Dev Biol. 2000;227:239-55.

Broekman DC, Frei DM, Gylfason GA, Steinarsson A, Jörnvall H, Agerberth B, Gudmundsson GH, Maier VH. Cod cathelicidin: isolation of mature peptide, cleavage site characterization and developmental expression. Dev Comp Immunol. 2011;35:296-303.

Budi EH, Duan D, Derynck R. Transforming growth factor- $\beta$ receptors and smads: regulatory complexity and functional versatility. Trends Cell Biol. 2017;27:658-72.

Chen J, Chen Q, Lu XJ, Chen J. The protection effect of LEAP-2 on the mudskipper (Boleophthalmus pectinirostris) against Edwardsiella tarda infection is associated with its immunomodulatory activity on monocytes/ macrophages. Fish Shellfish Immunol. 2016:59:66-76.

Cho YS, Lee SY, Kim KH, Kim SK, Kim DS, Nam YK. Gene structure and differential modulation of multiple rockbream (Oplegnathus fasciatus) hepcidin isoforms resulting from different biological stimulations. Dev Comp Immunol. 2009;33:46-58.

Fujimoto T, Kataoka T, Sakao S, Saito T, Yamaha E, Arai K. Developmental stages and germ cell lineage of the loach (Misgurnus anguillicaudatus). Zool Sci. 2006;23:977-89.

Glasuer SMK, Neuhauss SCF. Whole-genome duplication in teleost fishes and its evolutionary consequences. Mol Gen Genomics. 2014;289:1045-60.

Hancock RE, Haney EF, Gill EE. The immunology of host defence peptides: beyond antimicrobial activity. Nat Rev Immunol. 2016;16:321-34.

Henriques ST, Tan CC, Craik DJ, Clark RJ. Structural and functional analysis of human liver-expressed antimicrobial peptide 2. Chembiochem. 2010;11:2148-57.

Katzenback BA. Antimicrobial peptides as mediators of innate immunity in teleosts. Biology. 2015;4:607-39.

Kim DS, Jo JY, Lee TY. Induction of triploidy in mud loach (Misgurnus mizolepis) and its effect on gonad development and growth. Aquaculture. 1994;120:263-70.

Kim YU, Park YS, Kim DS. Development of eggs, larvae and juveniles of loach Misgurnus mizolepis Günther. Bull Kor Fish Soc. 1987;20:16-23.

Krause A, Sillard R, Kleemeier B, Klüver E, Maronde E, Conejo-García JR, et al. Isolation and biochemical characterization of LEAP-2, a novel blood peptide expressed in the liver. Protein Sci. 2003;12:143-52.

Lee SY, Nam YK. Isolation of novel hepcidin isoforms from the rockbream Oplegnathus fasciatus (Perciforomes). Fish Aquat Sci. 2011;14:31-42.

Li HX, Lu XJ, Li CH, Chen J. Molecular characterization and functional analysis of two distinct liver-expressed antimicrobial peptide 2 (LEAP-2) genes in large yellow croaker (Larimichthys crocea). Fish Shellfish Immunol. 2014;38:330-9.

Li HX, Lu XJ, Li CH, Chen J. Molecular characterization of the liver-expressed antimicrobial peptide 2 (LEAP-2) in a teleost fish, Plecoglossus altivelis: antimicrobial activity and molecular mechanism. Mol Immunol. 2015;65:406-15.

Li Y, Xiang Q, Zhang Q, Huang Y, Su Z. Overview on the recent study of antimicrobial peptides: origins, functions, relative mechanisms and application. Peptides. 2012;37:207-15.

Li Z, Hong WS, Qiu HT, Zhang YT, Yang MS, You XX, Chen SX. Cloning and expression of two hepcidin genes in the mudskipper (Boleophthalmus pectinirostris) provides insights into their roles in male reproductive immunity. Fish Shellfish Immunol. 2016;56:239-47.

Liang T, Ji W, Zhang GR, Wei KJ, Feng K, Wang WM, Zou GW. Molecular cloning and expression analysis of liver-expressed antimicrobial peptide 1 (LEAP-1) and LEAP-2 genes in the blunt snout bream (Megalobrama amblycephala). Fish Shellfish Immunol. 2013:35:553-63.

Liu F, Li JL, Yue GH, Fu JJ, Zhou ZF. Molecular cloning and expression analysis of the liver-expressed antimicrobial peptide 2 (LEAP-2) gene in grass carp. Vet Immunol Immunopathol. 2010;133:133-43.

Liu T, Gao Y, Wang R, Xu T. Characterization, evolution and functional analysis of the liver-expressed antimicrobial peptide 2 (LEAP-2) gene in miiuy croaker. Fish Shellfish Immunol. 2014;41:191-9.

Magnadóttir B. Innate immunity of fish (overview). Fish Shellfish Immunol. 2006;20:137-51.

Matsumoto N, Jubo A, Liu H, Akita K, Laub F, Ramirez F, Keller G, Friedman SL. Developmental regulation of yolk sac hematopoiesis by Krüppel-like factor 6 . Blood. 2006;107:1357-65.

Nam BH, Moon JY, Kim YO, Kong HJ, Kim WJ, Lee SJ, Kim KK. Multiple $\beta$-defensin isoforms identified in early developmental stages of the teleost Paralichthys olivaceus. Fish Shellfish Immunol. 2010;28:267-74.
Nam YK, Cho YS, Lee SY, Kim BS, Kim DS. Molecular characterization of hepcidin gene from mud loach (Misgurnus mizolepis; Cypriniformes). Fish Shellfish Immunol. 2011;31:1251-8.

Nam YK, Noh JK, Cho YS, Cho HJ, Cho KN, Kim CG, Kim DS. Dramatically accelerated growth and extraordinary gigantism of transgenic mud loach Misgurnus mizolepis. Transgenic Res. 2001;10:353-62.

Padhi A, Verghese B. Evidence for positive Darwinian selection on the hepcidin gene of perciform and pleuronectiform fishes. Mol Divers. 2007;11:119-30.

Panganiban G, Rubenstein JLR. Developmental function of the Distal-less/Dlx homeobox genes. Development. 2002;129:4371-86.

Ren G, Shen WY, Li WF, Zhu YR. Molecular characterization and expression pattern of a liver-expressed antimicrobial peptide 2 (LEAP-2) gene in yellow catfish (Pelteobagrus fulvidraco). J Aquacult Res Dev. 2014;5:229.

Schmittgen TD, Livak KJ. Analyzing real-time PCR data by the comparative CT method. Nat Protoc. 2008:3:1101-8.

Townes CL, Michailidis G, Hall J. The interaction of the antimicrobial peptide CLEAP-2 and the bacterial membrane. Biochem Biophys Res Commun. 2009;387:500-3.

Truksa J, Lee P, Beutler E. Two BMP responsive elements, STAT, and bZIP/HNF4/ COUP motifs of the hepcidin promoter are critical for BMP, SMAD1, and HJV responsiveness. Blood. 2009;113:688-95.

Yang G, Guo H, Li H, Shan S, Zhang X, Rombout JHWM, An L. Molecular characterization of LEAP-2 CDNA in common carp (Cyprinus carpio L.) and the differential expression upon a Vibrio anguillarum stimulus: indications for a significant immune role in skin. Fish Shellfish Immunol. 2014;37:22-9.

Yang M, Wang KJ, Chen JH, Qu HD, Li SJ. Genomic organization and tissue specific expression analysis of hepcidin-like genes from black porgy (Acanthopagrus schlegelii B). Fish Shellfish Immunol. 2007;23:1060-71.

Zhang YA, Zou J, Chang Cl, Secombes CJ. Discovery and characterization of two types of liver-expressed antimicrobial peptide 2 (LEAP-2) genes in rainbow trout. Vet Immunol Immunopathol. 2004;101:259-69.

\section{Submit your next manuscript to BioMed Central and we will help you at every step:}

- We accept pre-submission inquiries

- Our selector tool helps you to find the most relevant journal

- We provide round the clock customer support

- Convenient online submission

- Thorough peer review

- Inclusion in PubMed and all major indexing services

- Maximum visibility for your research

Submit your manuscript at www.biomedcentral.com/submit
Biomed Central 